\title{
PENGGUNAAN ALAT KONTRASEPSI OLEH AKSEPTOR DI RUMAH SAKIT MANADO MEDICAL CENTER PERIODE JULI-DESEMBER 2018
}

\author{
Melisa P. Sinyal \\ Sefti Rompas \\ Yolanda Bataha \\ Program Studi Ilmu Keperawatan Fakultas Kedokteran \\ Universitas Sam Ratulangi Manado \\ Email : $\underline{\text { SMelisapatrisia04@gmail.com }}$
}

\begin{abstract}
Contraception is an action that helps an individual or a married couple to get a certain objective, avoid unwanted births, get the desired birth, set the interval between pregnancies, control the time of birth and determine the number of children in the family. The purpose of this study was to determine the description of contraceptive use by acceptors at Manado Medical Center Hospital in the period July-December 2018. Samples in this study were 58 respondents. This research design is a type of descriptive study with a retrospective research design. The results of the using contraception according to age, the most are age 2630 years and $>30$ years, then age 19-25 years. According to the level of education, there are more educated high school and S1 than junior high school. Whereas according to work, there are more people who work as entrepreneurs compared to civil servants/private sector, employees and IRTs. The most widely used contraception is injection contraception. Conclusion of this research is that injection contraception is the most widely used contraceptive device at Manado Medical Center Hospital in the period July-December 2018. Keywords : Contraception, Acceptors, Age, Knowledge, Job.
\end{abstract}

\begin{abstract}
Abstrak : Kontrasepsi adalah tindakan yang membantu individu atau pasangan suami istri untuk mendapatkan objektif tertentu, menghindari kelahiran yang tidak diinginkan, mendapatkan kelahiran yang memang diinginkan, mengatur interval di antara kehamilan, mengontrol waktu saat kelahiran dan menentukan jumlah anak dalam keluarga. Tujuan penelitian ini untuk mengetahui gambaran penggunaan alat kontrasepsi oleh akseptor di Rumah Sakit Manado Medical Center periode Juli-Desember 2018. Sampel dalam penelitian ini adalah 58 responden. Desain Penelitian ini adalah Jenis penelitian deskriptif dengan desain penelitian retrospektif. Hasil Penelitian penggunaan alat kontrasepsi menurut umur, yang paling banyak adalah umur 26-30 tahun dan >30 tahun, kemudian umur 19-25 tahun. Menurut tingkat pendidikan yaitu lebih banyak yang berpendidikan SLTA dan S1 dibandingkan SLTP. Sedangkan menurut pekerjaan, adalah lebih banyak yang bekerja sebagai wiraswasta dibandingkan PNS/swasta, karyawan dan IRT. Kontrasepsi yang paling banyak digunakan yaitu kontrasepsi suntik. Kesimpulan bahwa alat kontrasepsi suntik adalah alat kontrasepsi yang paling banyak digunakan di Rumah Sakit Manado Medical Center periode Juli-Desember 2018.
\end{abstract}

Kata Kunci : Kontrasepsi, Umur, Pendidikan, Pekerjaan. 


\section{PENDAHULUAN}

Kontrasepsi adalah tindakan yang membantu individu atau pasangan suami isteri untuk mendapatkan objektif tertentu, menghindari kelahiran yang tidak diinginkan, mendapatkan kelahiran yang memang diinginkan, mengatur interval diantara kehamilan, mengontrol waktu saat kelahiran dalam hubungan dengan umur suami isteri dan menentukan jumlah anak dalam keluarga (BKKBN, 2009). Menurut BKKBN (2013), penggunaan alat kontrasepsi terbanyak yaitu Thailand $80 \%$, Kamboja 79\%, Vietnam $78 \%$.

Tingginya pertumbuhan penduduk di Indonesia merupakan masalah utama yang dihadapi Indonesia. Jumlah penduduk Indonesia tahun 2010 sebanyak 237,6 juta jiwa, tahun 2011 sebanyak 241 juta jiwa, dan sampai dengan bulan Maret tahun 2013 mencapai 248,4 juta jiwa. Selama rentang tahun 2000 - 2010, laju pertumbuhan penduduk Indonesia sebesar $1,49 \%$ per tahun. Angka ini mengalami kenaikan dibanding periode tahun 1999 - 2000 yang masih sebesar 1,45\% (BKKBN, 2013). Semakin tinggi pertumbuhan penduduk semakin besar usaha yang dilakukan untuk mempertahankan kesejahteraan rakyat. Oleh karena itu pemerintah terus berupaya untuk menekan laju pertumbuhan dengan Program Keluarga Berencana.

Persentase peserta KB di Indonesia tahun 2002-2003 mencapai 59,5\% terdiri dari beberapa metode kontrasepsi yaitu suntik $(27,8 \%)$, pil $(13,2 \%)$, IUD $(6,2 \%)$, susuk $(4,3 \%)$, kondom $(0,9 \%)$, tubektomi $(3,7 \%)$, dan vasektomi $(0,4 \%)$. Sedangkan pada tahun 2007, prevalensi peserta KB di Indonesia sebanyak 66,2\%. Terdiri dari suntik (34\%), pil (17\%), IUD (7\%), implant (7\%), MOW (2,6\%), MOP (0,3\%), dan kondom $(0,6 \%)$ (BKKBN, 2008). Menurut analisis data kependudukan dan KB hasil SUSENAS tahun 2015, dari jumlah PUS sebesar 48,609 juta pasangan, 29,155 juta atau 59,98\% merupakan PUS yang ikut KB semua cara, sedangkan PUS yang mengikuti cara KB modern mencapai $58,99 \%$ dari total PUS. Diprovinsi Sulawesi
Utara penggunaan alat kontrasepsi modern sebanyak 65,91\%.

Metode kontrasepsi yang ada dalam program KB di Indonesia terbagi menjadi lima yaitu, metode kontrasepsi sederhana, metode kontrasepsi hormonal, metode kontrasepsi dengan Alat Kontrasepsi Dalam Rahim (AKDR) atau IUD (Intra Uterine Device), metode kontrasepsi mantap dan metode darurat. Tersedianya akses informasi dan pelayanan $\mathrm{KB}$, dapat mencegah kehamilan yang tidak di inginkan. Jika semua perempuan mempunyai akses terhadap kontrasepsi yang aman dan efektif, diperkirakan akan menurunnya resiko kesehatan reproduksi yang terkait dengan kehamilan, persalinan dan aborsi tidak aman. Sampai sekarang cara kontrasepsi yang ideal belum ada. Suatu metode kontrasepsi sebaiknya haruslah aman, berdaya guna, dapat diterima bukan hanya oleh klien tetapi juga oleh lingkungan budaya dimasyarakat dan bila metode tersebut dihentikan penggunaannya, klien akan segera kembali kesuburannya, dipercaya, murah dan terakhir dapat diterima penggunaannya oleh pasangan.

Adapun data yang didapat dari Rumah Sakit Manado Medical Center yang merupakan salah Rumah Sakit yang dilengkapi dengan pelayanan Keluarga Berencana dimana terdapat sebanyak 122 akseptor pengguna kontrasepsi periode Juli - Desember 2018. Akseptor yang menggunakan kontrasepsi suntik sebanyak 108 akseptor, yang menggunakan kontrasepsi IUD sebanyak 13 akseptor dan yang menggunakan kontrasepsi implant seebnyak 2 akseptor. Banyak faktor yang memengaruhi pemakaian alat kontrasepsi antara lain pendapatan/ekonomi, umur, pendidikan, keluarga, pekerjaan, efek samping, kegagalan kontrasepsi, tetapi dalam penelitian ini, peneliti hanya membatasi pada gambaran dalam pemakaian alat kontrasepsi menurut umur, tingkat pendidikan dan pekerjaan. Berdasarkan uraian diatas maka peneliti tertarik untuk melakukan penelitian dengan 
judul "Gambaran penggunaan alat kontrasepsi oleh akseptor di Rumah Sakit Manado Medical Center periode Juli Desember 2018"

\section{METODE PENELITIAN}

Penelitian yang dilakukan adalah penelitian deskriptif dengan pendekatan retrospectif, yaitu merupakan penelitian yang berusaha melihat ke belakang, artinya pengumpulan data dimulai dari efek atau akibat yang telah terjadi (Notoatmodjo, 2005). Penelitian ini dilaksanakan di Rumah Sakit Manado Medical Center. Penelitian dilaksanakan pada bulan Desember 2018. Populasi dalam penelitian ini adalah seluruh akseptor yang menggunakan alat kontrasepsi di Rumah Sakit Manado Medical Center. Jumlah sampel dalam penelitian ini yaitu 58 sampel. Instrumen yang digunakan adalah lembar observasi.

Tahapan dalam mendapatkan data yang benar dan mempermudah proses pengolahan data, dilakukan tahapan editing, coding, tabulating, cleaning. Analisis data dalam penelitian ini, peneliti melakukan analisa data dengan analisa univariat. Analis univariat menggunakan tehknik statistik analitik dalam bentuk presentase untuk masing - masing sub variable dengan terlebih dahulu menggunakan jenjang kategori (Notoatmodjo, 2005). Analisa ini bertujuan untuk melihat tampilan distribusi, frekuensi dan presentase dari tiap-tiap variable, dalam penelitian ini adalah umur, tingkat pendidikan, pekerjaan dan penggunaan alat kontrasepsi.

Peneliti juga memperhatikan masalah masalah etika penelitian yang meliputi : Informed Consent berisi pernyataan persetujuan sebagai subyek, yang diisi secara sukarela oleh subjek penelitian; Anonimity (Tanpa Nama) untuk menjaga privasi dan kerahasiaan subjek penelitian; dan Confidentiality menjaga informasi dan hasil penelitian dari orang yang tidak berhak mengakses kerahasiaan informasi responden (Nursalam, 2008).
HASIL dan PEMBAHASAN

Tabel 1. Distribusi Frekuensi Berdasarkan Umur

\begin{tabular}{ccc}
\hline $\begin{array}{c}\text { Karakteristik } \\
\text { Umur }\end{array}$ & n & \% \\
\hline $19-25$ & 18 & 31,0 \\
$26-30$ & 20 & 34,5 \\
$>30$ & 20 & 34,5 \\
\hline Total & $\mathbf{5 8}$ & $\mathbf{1 0 0}$ \\
\hline
\end{tabular}

Sumber : Data Primer, 2018

Jumlah responden pada table 1, yang paling banyak adalah responden yang berumur 2630 tahun yaitu 20 orang $(34,5 \%)$, responden yang memiliki umur $>30$ tahun yaitu 20 orang, sedangkan yang paling sedikit yaitu berumur 19 - 25 tahun sebanyak 18 orang $(31,0 \%)$.

Tabel 2. Distribusi Frekuensi Berdasarkan Pendidikan

\begin{tabular}{ccc}
\hline $\begin{array}{c}\text { Karakteristik } \\
\text { Pendidikan }\end{array}$ & n & \% \\
\hline SLTP & 12 & 20,7 \\
SLTA & 23 & 39,7 \\
S1 & 23 & 39,7 \\
\hline Total & $\mathbf{5 8}$ & $\mathbf{1 0 0}$ \\
\hline
\end{tabular}

Sumber : Data Primer, 2018

Data yang di paparkan pada tabel 2, dari 58 jumlah responden yang paling banyak berpendidikan SLTA yaitu 23 orang $(39,7 \%)$ dan S1 yaitu 23 orang $(39,7 \%)$ dan yang paling sedikit berpendidikan SLTP yaitu sebanyak 12 orang (20\%).

Tabel 3. Distribusi Frekuensi Berdasarkan Pekerjaan

\begin{tabular}{ccc}
\hline $\begin{array}{c}\text { Karakteristik } \\
\text { Pekerjaan }\end{array}$ & $\mathbf{n}$ & $\mathbf{\%}$ \\
\hline Wiraswasta & 20 & 34,5 \\
PNS/Sawasta & 14 & 24,1 \\
Karyawan & 14 & 24,1 \\
IRT/Tidak Bekerja & 10 & 17,2 \\
\hline Total & $\mathbf{5 8}$ & $\mathbf{1 0 0}$ \\
\hline
\end{tabular}

Sumber : Data Primer, 2018

Data pada tabel 3, dari 58 responden jumlah responden yang paling banyak adalah 
responden yang bekerja sebagai wiraswasta yaitu sebanyak 20 orang $(34,5 \%)$, responden yang memiliki pekerjaan sebagai PNS/Swasta sebanyak 14 orang $(24,1 \%)$, sama halnya dengan responden yang memiliki pekerjaan sebagai Karyawan sebanyak 14 orang $(24,1 \%)$ dan paling sedikit bekerja sebagai IRT/Tidak bekerja yaitu sebanyak 10 orang $(17,2 \%)$.

Tabel 4. Distribusi Frekuensi Penggunaan Alat Kontrasepsi

\begin{tabular}{ccc}
\hline $\begin{array}{c}\text { Alat } \\
\text { Kontrasepsi }\end{array}$ & $\mathbf{n}$ & $\mathbf{\%}$ \\
\hline Suntik & 50 & 86,2 \\
IUD & 7 & 12,1 \\
Implant & 1 & 1,7 \\
\hline Total & $\mathbf{5 8}$ & $\mathbf{1 0 0}$ \\
\hline
\end{tabular}

Sumber : Data Primer, 2018

Jumlah responden pada tabel 4, dari 58 responden pengguna alat kontrasepsi yang paling banyak digunakan yaitu kontrasespsi suntik yaitu sebanyak 50 orang $(82,2 \%)$, kemudian kontrasepsi IUD sebanyak 7 orang $(12,1 \%)$, sedangkan yang paling sedikit digunakan yaitu kontrasepsi implant sebanyak 1 orang $(1,7 \%)$.

\section{Karakteristik Responden}

Berdasarkan hasil penelitian menunjukkan, dari jumlah responden 58 orang, yang menggunakan alat kontrasepsi tebanyak pada kelompok umur antara 26-30 tahun sebanyak 20 orang $(34,5 \%)$ dan umur antara $>30$ tahun sebanyak 20 orang (34,5\%), pada kelompok umur 19-25 tahun sebanyak 18 orang $(31,0 \%)$ menempati urutan terendah. Hasil penelitian ini sejalan dengan hasil Survei Demografi dan Kesehatan Indonesia (2012), bahwa wanita muda yang paling banyak menggunakan alat kontrasepsi. Menurut hasil penelitian Agustini (2015), bahwa wanita di bawah 30 tahun cenderung menjarangkan kehamilan sementara yang berumur $>30$ tahun diharapkan untuk mengakhiri kehamilan. Maka dari itu bertambahnya umur maka semakin berkembang pula daya tangkap dan pola pikir seseorang sehingga semakin banyak pula pengetahuan yang diperoleh. Menurut teori dari Notoatmodjo (2003), umur berpengaruh terhadap daya tangkap dan pola pikir seseorang. Penelitian ini menunjukan dengan umur yang matang seseorang sudah mampu memutuskan berkeluarga dan kemudian memilih untuk menggunakan alat kontrasepsi. Pendewasaan umur juga berkaitan dengan pengendalian kelahiran karena lamanya masa subur perempuan terkait dengan banyaknya anak yang akan dilahirkan. Semakin tua umur seseorang maka pemilihan alat kontrasepsi ke arah alat yang mempunyai efektivitas lebih tinggi yakni metode kontrasepsi jangka panjang (BKKBN, 2013).

Hasil penelitian pada 58 responden di dapatkan bahwa responden terbanyak berpendidikan SLTA 23 akseptor (39,7\%), dan S1 sebanyak 23 akseptor $(39,7 \%)$. Sedangkan yang berpendidikan SLTP sebanyak 12 akseptor (20,7\%). Pendidikan pada dasarnya merupakan usaha untuk mengembangkan pengetahuan, sikap, dan keterampilan. Menurut Notoatmodjo (2003), umumnya makin tinggi tingkat pendidikan seseorang makin mudah seseorang menerima informasi baik dari lingkungan sosial ataupum melalui sosial media. Hasil tersebut di dukung dengan data dari Kementrian Kesehatan (2017), menunjukan bahwa yang menggunakan alat kontrasepsi paling banyak bependidikan SLTA. Hasil penelitian ini sama dengan hasil penelitian Pastuti (2007), bahwa antara tingkat pendidikan dengan penggunaan kontrasepsi atau KB menunjukkan hubungan yang bermakna. Hal ini di sebabkan karenea pendidikan merupakan salah satu faktor yang sangat menentukan pengetahuan dan persepsi seseorang terhadap pentingnya sesuatu hal, termasuk pentingnya dalam keikutsertaan untuk menggunakan alat kontrasepsi. Hasil ini menunjukkan dengan tingkat pendidikan yang baik maka akan membantu akseptor dalam memahami informasi - informasi yang berhubungan penggunaan kontrasepsi. 
Berdasarkan pekerjaan responden, terbanyak bekerja sebagai Wiraswasta berjumlah 20 orang $(34,5 \%)$. Yang bekerja sebagai PNS/Swasta sebanyak 14 orang $(24,1 \%)$ kemudian yang bekerja sebagai Karyawan sebanyak 14 orang $(24,1 \%)$, dan yang terakhir sebagai IRT sebanyak 10 orang $(17,2 \%)$. Wanita yang bekerja memiliki waktu yang mahal sehingga kesempatan untuk mengurus anak lebih sedikit dibandingkan wanita yang tidak bekerja, sehingga wanita yang bekerja akan cenderung membatasi jumlah anak.

Hasil penelitian Shindhy (2017), menunjukan bahwa wanita yang menggunakan alat kontrasepsi adalah lebih banyak yang bekerja. Hasil ini menunjukan wanita yang bekerja juga bisa menambah pengalaman dan pengetahuan dibandingkan dengan wanita yang tidak bekerja lebih sedikit memiliki informasi dari pada wanita yang bekerja. Sesusai dengan teori Kutanegara, dkk, (2010), dikatakan bahwa secara umum jumlah pemakaian kontrasepsi bagi wanita bekerja lebih tinggi daripada wanita yang tidak bekerja. Wanita yang bekerja kebanyakan menghabiskan waktu di tempat bekerja seperti wiraswasta, PNS/swasta, dan karyawan. Mereka yang bekerja selama kurang lebih 10 jam, mengakibatkan mereka kurang memiliki waktu untuk mengurus anak. Maka dari itu mereka menggunakan alat kontrasepsi untuk mengontrol kehamilan.

\section{Penggunaan Alat Kontrasespsi}

Kontrasepsi adalah segala macam alat yang digunakan untuk mencegah terjadinya kehamilan sebagai akibat pertemuan sel sperma dan sel telur (ovum) yang sudah matang. Dalam hasil penelitian ini diperoleh gambaran penggunaan kontrasepsi, menunjukkan dari 58 responden, terdapat 50 responden $(86,2 \%)$ yang menggunakan kotrasepsi suntik, kemudian sebanyak 7 responden $(12,1 \%)$ yang menggunakan kotrasepsi IUD, dan sebanyak 1 responden $(1,7 \%)$ yang menggunakan kontrasespsi implant. Pemakaian alat kontrasepsi merupakan salah satu bentuk perilaku kesehatan, terutama pada perempuan.

Bedasarkan hasil penelitian, sekitar $80 \%$ akseptor menggunakan metode kontrasepsi suntik, sebab metode ini dapat diandalkan, dan dapat dengan mudah kembali subur. Hasil Riskesdas tahun 2013, pemakaian alat $\mathrm{KB}$ di Indonesia sebesar $59,7 \%$. Diantara penggunaan KB modern tersebut, sebagian besar menggunakan cara KB suntikan (Departemen Kesehatan, 2013). Akseptor pengguna kontrasepsi kebanyakan memilih kontrasepsi suntik karena memiliki efek samping yang sedikit, murah, praktis dan nyaman. Jika akseptor ingin berhenti, cukup hentikan saja tanpa harus ke rumah sakit. Akseptor yang memilih menggunakan kontrasepsi suntik kemungkinan menginginkan untuk menunda kehamilan atau tidak ingin hamil lagi dan kemudahan penggunaan dari pada keefektifan kontrasepsi. Pada umumnya akseptor lebih memilih metode kontrasepsi suntik, karena alasan praktis yaitu sederhana dan tidak perlu takut lupa dan juga untuk merencanakan kehamilan. Kontrasepsi suntik memiliki efektifitas yang tinggi bila penyuntikan dilakukan secara teratur dan sesuai jadwal yang telah ditentukan (Saifuddin, 2003).

Biaya merupakan salah satu faktor pertimbangan akseptor untuk menggunakan kontrasepsi IUD, terlebih bagi yang berpenghasilan rendah yang merasa terbeban dengan biaya yang harus di keluarkan. Menurut hasil penelitian Septalia (2014), biaya pemakaian kontrasepsi berpengaruh signifikan terhadap pemilihan metode kontrasepsi. Biaya menjadi salah satu alasan akseptor memilih kontrasepsi IUD. Karena sebagian besar persepsi akseptor $\mathrm{KB}$ cenderung melihat dari biaya yang di keluarkan saat akan menggunakan alat kontrasepsi.

Menurut SDKI tahun 2012, akseptor memilih menggunakan IUD karena meningkatnya pengetahuan mereka tentang kontrasepsi tersebut (Departemen Kesehatan, 2014). Menurut asumsi peneliti rendahnya minat wanita usia subur terhadap 
IUD tidak terlepas dari rendahnya pengetahuan terhadap alat kontrasepsi tersebut. Sehingga sangat perlu pemahaman yang baik tentang IUD bagi wanita usia subur. Akseptor kontrasepsi IUD kemungkinan paham dan mengerti dengan kontrasepsi ini, maka dari itu mereka dengan nyaman untuk menggunakan kontrasepsi IUD. Karena jika di lihat, mayoritas pendidikan akseptor yang menggunakan kontrasepsi IUD adalah yang mereka berpendidikan SLTA dan S1. Pengetahuan dapat ditingkatkan oleh petugas kesehatan lewat memberikan penyuluhan tentang KB. Pengetahuan seseorang tentang IUD bisa didapat melalui pengalaman atau pendidikan serta pemahamannya terhadap IUD. Semakin tinggi pengetahuan seseorang maka pemahamannya terhadap IUD akan semakin baik.

Kontrasepsi implant adalah kontrasepsi yang di tanam di bawah kulit (Nina, 2013). Sama halnya dengan kontrasepsi suntik dan IUD kontrasepsi implant juga berguna untuk menjarakkan kehamilan. Akseptor memilih kontrasepsi ini karena kontrasepsi implant bisa di gunakan oleh semua wanita dalam usia reproduksi, juga tidak mengganggu aktifitas dalam berhubungan suami istri. Untuk wanita yang bekerja kontrasepsi ini sangat cocok, karena pekerjaan mempengaruhi seseorang dalam menggunakan kontrasepsi. Hasil penelitian ini sejalan dengan penelitian Dona (2014), bahwa ada pengaruh antara pekerjaan terhadap pemakaian kontrasepsi implant. Menurut asumsi peneliti, kesibukan pekerjaan merupakan salah satu alasan pengguna menggunakan kontrasepsi implant. Karena orang yang bekerja lebih suka mengunakan hal yang lebih lama karena tidak suka mengingat-ngingat dan orang yang bekerja memerlukan banyak waktu dan tenaga. Maka dari itu akseptor memilih menggunakan kontrasepsi agar tidak mengganggu kesibukan mereka dengan mencegah atau mengontrol kehamilan, karena mereka akan lebih banyak menghabiskan waktu dengan pekerjaan mereka.

\section{SIMPULAN}

Berdasarkan hasil penelitian yang sudah di lakukan di Rumah Sakit Manado Medical Center, dapat di simpulkan bahwa:

1. Penggunaan alat kontrasepsi menurut tingkat pendidikan adalah yang paling banyak adalah SLTA kemudian S1 dan yang paling sedikit adalah SLTP. Kemudian menurut pekerjaan adalah yang paling banyak bekerja sebagai wiraswasta, di ikuti PNS/swasta, kemudian karyawan dan terakhir IRT/tidak bekerja.

2. Penggunaan alat kontrasepsi tebanyak adalah kontrasepsi suntik, diikuti kontrasepsi IUD dan yang terakhir kontrasepsi implant.

\section{DAFTAR PUSTAKA}

Agustini R. 2015. Kesesuaian Penggunaan Alat Kontrasepsi Berdasarkan Permintaan KB pada Pasangan Usia Subur (PUS) di Kecamatan Puger Kabupaten Jember. https://jurnal.unej.ac.id/index.php/J PK/article/view/2519.

BKKBN. (2008). Program KB di Indonesia.

BKKBN. (2009). Profil BKKBN Tahun 2009. https://www.bkkbn.go.id/

BKKBN. (2013). Jurnal Keluarga Berencana 2012.

Departemen Kesehatan. (2013). Laporan Riskesdas 2013. (http://labmandat.litbang.depkes.go. id/images/download/laporan/RKD/ 2013/Laporan_riskesdas_2013_fina 1.pdf.

Departemen Kesehatan. (2014). Buletin Kespro. www.depkes.go.id/download.php?f ile $=$ download/pusdatin/...pdf. 
Dona P. (2014). Faktor - Faktor Yang Mempengaruhi Akseptor KB Implant Terhadap Pemakaian Kontrasepsi Implant Diklinik Ardianti Desa Suka Karya Kecamatan Simeulue TimurKabupaten Simulue. http://simtakp.uui.ac.id/docjurnal/D ONA_RATNA_PUSPITAjurnal.pdf.

Kementrian Kesehatan. (2017). Kespro dan KB Komprehensip. (http://bppsdmk.kemkes.go.id/pusdi ksdmk/wpcontent/uploads/2017/08/Kesprodan-KB-Komprehensif.pdf)

Kutanegara, dkk. (2010). Keluarga Berencana Dan Kesehatan Reproduksi.

Yogyakarta. Pustaka Belajar.

Nina S. Mulyani, SST. 2013. Keluarga Berencana dan Alat Kontrasepsinya. Yogjakarta : Nuha Medika.

Notoatmojo, S. (2003). Ilmu Kesehatan

Masyarakat: Prinsip-Prinsip

Dasar. Jakarta: Rineka Cipta. 2003

Notoatmodjo. 2005. Metodologi Penelitian Kesehatan. Jakarta: PT. Rineka Cipta.

Nursalam. (2008). Proses \& Dokumentasi Keperawatan, Konsep \& Praktik. Jakarta: Salemba Medika.

Pastuti R. (2007).Determinan Penggunaan Metode Kontrasepsi IUD di Indonesia Analisis Data SDKI 2002-2003.

https://journal.ugm.ac.id/bkm/articl e/view/3627.
Saifuddin. (2003). Buku Panduan Praktis Pelayanan Kontrasepsi. Jakarta; YBP-SP.

Survei Demografi dan Kesehatan Indonesia (SDKI). (2012). Survei Demografi dan Kesehatan Indonesia 2012. http://chnrl.org/pelatihandemografi/SDKI-2012.pdf

Septalia R. (2016). Faktor yang Memengaruhi Pemilihan Metode Kontrasepsi. https://ejournal.unair.ac.id/JBK/article/view 15828 .

Shindhy D. (2017). Faktor-Faktor Yang Berhubungan Dengan Pemilihan Alat Kontrasepsi Intra Uterine Devices (IUD) Pada Ibu Di Kecamatan Bantul Yogyakarta. digilib.unisayogya.ac.id/2638/ 